outcome in oligohydramnios due to membrane rupture in the second trimester. Lancet 1987:ii:129-31.

$\mathrm{M}$ Bioti and A Greenough Department of Child Health. Frederic Still Neonatal Intensive Care Unit, King's College School of Medicine and Dentistry. London SE5 9PJ

\section{Marfan's syndrome in mitral valve disease}

Sir,

We read with interest the report by Marlow et al on an infant with Marfan's syndrome and mitral valve dysfunction who died after acute illness with gross cardiac failure. ${ }^{1}$ The authors stated that 'disease affecting the mitral valve is usually more benign than that of the aortic valve ....

This statement, however, may not be applicable to infants and young children with Marfan's syndrome. We have recently reported on the clinical course and the echocardiographic findings in 25 children with this syndrome. ${ }^{2}$ Prolapse of the mitral valve leaflets was shown by echocardiography in all the patients and aortic pathology in $80 \%$ of the cases. Five patients died during the follow up period (mean $5 \pm 4.5$ years); two of them were infants with severe mitral insufficiency and progressive congestive heart failure. The other three patients died during the second decade of life from complications of the aortic pathology. Another series reported by Sisk et al showed that among 15 patients with Marfan's syndrome diagnosed before 4 years of age, mitral valve dysfunction was the leading cause of cardiovascular morbidity and mortality. ${ }^{3}$

These data indicate that mitral valve disease is the most common cause of congestive heart failure and death in infants and young children with Marfan's syndrome.

\section{References}

1 Marlow N, Gregg JEM, Qureshi SA. Mitral valve disease in Marfan's syndrome. Arch Dis Child 1987:62:960-2

2 Geva T, Hegesh J, Frand M. The clinical course and echocardiographic features of Marfan's syndrome in childhood. Am J Dis Child 1987;141:1179-82.

${ }^{3}$ Sisk HE, Zahka KG, Pyeritz RE. The Marfan's syndrome in early childhood: analysis of 15 patients at less than 4 years of age. Am J Cardiol 1983;52:353-8.

T Geva and M Frand Department of Pediatrics C, The Chaim Sheba Medical Center. Tel Hashomer 52621 and Sackler School of Medicine, Tel Aviv University. Israel

\section{Medical staffing in paediatric departments in district general hospitals}

Sir,

Dr Nelson is right. ${ }^{1}$ At this hospital we have only two senior house officers, often with no previous paediatric experience, on a 1:2 rota, without any intermediate cover. to cover general and neonatal wards including labour ward resuscitation. We do not therefore have a 1:3 rota, nor a "safety net'. Five years of local discussions have not altered this. What is needed is a united and forceful voice from the British Paediatric Association nationally, coupled with specific advice for consultant paediatricians on how to get past the embargoes on increasing junior staff.

\section{Reference \\ 1 Nelson R. Medical staffing in paediatric departments in district general hospitals. Arch Dis Child 1988;63:96-7. \\ F N Porter and C S Nanayakkara Grantham and Kesteven General Hospital, Grantham, Lincolnshire NG31 $8 D G$ \\ Maternal narcotic abuse and the newborn}

Sir,

We were interested in the report by AIRoomi et al concerning maternal narcotic abuse and its effects on newborn infants. ${ }^{1}$ Women on Merseyside smoke heroin rather than inject it and we would like to report aspects of our experience of 37 infants born to women who inhaled heroin.

(1) AIRoomi et al used phenobarbitone and chloral as first line drugs for the treatment of symptoms, but they make no comment on the effectiveness of these agents. In our series $15(40 \%)$ babies also developed withdrawal signs but our initial experience with phenobarbitone by injection was disappointing. We subsequently tried oral chlorpromazine, which we stopped using because of its epileptogenic potential, although it was effective. We now consider that treatment with pure aqueous morphine sulphate (0.125 $\mathrm{mg}$ ) given orally and as required is pharmacologically appropriate, have found it effective, and would recommend its use.

(2) In our series only eight $(22 \%)$ children were subject to legal constraints, compared with $38 \%$ in AlRoomi's series. While this may simply reflect a different approach to social management, it may be that heroin abuse by inhalation has less disruptive effects on family life.

(3) We also found that these children were not brought to hospital for follow up appointments. We now consider that community based surveillance is more appropriate.

\section{Reference}

1 AIRoomi LG. Davidson J. Evans TJ. Galea P, Howat R. Maternal narcotic abuse and the newborn. Arch Dis Child 1988:63:81-3

J E M Gregg, D C Davidson, and A M Weindling Fazakerley Hospital, Liverpool L9 7AL 